\title{
Maximizing Natural Trembling Aspen Seedling Establishment on a Reclaimed Boreal Oil Sands Site ${ }^{\text {}}$
}

\author{
Bradley D. Pinno and Ruth C. Errington
}

\begin{abstract}
Actively facilitating the natural establishment of trees on reclamation sites is seen as an important step in ecosystem recovery after oil sands mining. We examined the effect of different reclamation prescriptions, including two soil types (peat-mineral mix and forest floor-mineral mix) and two fertilizer levels (200 kg N ha-1 and no fertilizer), on naturally established trembling aspen (Populus tremuloides) seedlings and other deciduous trees. Aspen has a tiny, windblown seed which is very sensitive to moisture stress during establishment. Seedling establishment was greatest on peat-mineral mix soil with no fertilizer application and was related to the increased surface roughness and soil moisture and lack of vegetation competition with this soil prescription. Surprisingly, seedling establishment was not related to microsite characteristics such as concavity. Once established, average seedling height was not significantly different among soil types or fertilization treatments. Overall, using peat-mineral mix soil and increasing surface roughness offer a starting point for developing best management practices for facilitating natural deciduous tree seedling establishment in this region.
\end{abstract}

Keywords: land reclamation, forest floor-mineral mix, peat-mineral mix, Populus tremuloides, surface roughness, ecosystem development

I

and reclamation after oil sands mining in Alberta, $\triangle$ Canada requires the re-establishment of native plant communities characteristic of natural boreal forests in the region (Alberta Environment 2010). An important component of this goal is establishing trees on site, in particular, early successional deciduous trees which quickly develop shading leaf area and produce yearly litter fall, thereby aiding the development of a natural understory plant community and a functioning soil-plant nutrient cycle (Rowland et al. 2009, Macdonald et al. 2012). In the boreal mixedwood forest, trembling aspen (Populus tremuloides) and balsam poplar (Populus balsamifera) are the most common deciduous trees and normally regenerate from root suckers after natural disturbances such as wildfire or anthropogenic disturbances such as timber harvesting (Frey et al. 2003). However, this is not a viable regeneration option on reclaimed sites which have completely disturbed soil and no intact root systems. Planting trees is a common regeneration method on reclaimed oil sands sites but there have been issues with sourcing reliable

(2) This articles is freely available online at: http://er.uwpress.org

Ecological Restoration Vol. 33, No. 1, 2015

ISSN 1522-4740 E-ISSN 1543-4079

(O2015 by the Board of Regents of the University of Wisconsin System. aspen planting stock and planting trees can be an expensive operation. Therefore, if reclamation practices can be developed that optimize natural seedling establishment and the probabilities of success quantified, natural deciduous tree seedling establishment may become a viable reclamation option (Clewell and McDonald 2009).

Trembling aspen is a prolific seed producer with very small seeds easily blown by the wind and a maximum effective dispersal distance of $500 \mathrm{~m}$ to several $\mathrm{km}$ (USDA 2008). Aspen seeds have no dormancy requirements but do require adequate soil moisture during germination and early seedling growth (Barnes 1966, McDonough 1979, Fechner et al. 1981). Sensitivity to even mild water deficits results in few seeds progressing past the incipient germination stage (McDonough 1979) but aspen seedlings also do not tolerate standing water (Kay 1993), indicating that very specific soil moisture conditions must be met for successful natural seedling establishment. Balsam poplar have a slightly larger potential establishment niche but still require a constant supply of water for successful seedling establishment (Wolken et al. 2010). When soil moisture is adequate, seedling emergence occurs equally well on a variety of different substrates including mineral soil and aspen litter (McDonough 1979) but relatively greater seedling establishment has been found on less fertile soils (Turner et al.2003). At the microsite scale, aspen seedlings 
have been shown to prefer concave microsites rather than convex (Landhäusser et al. 2010), and have a low tolerance for vegetation competition during establishment (Kay 1993, Turner et al. 2003). The response of aspen seedlings to both microsite concavity and competition is likely related to moisture availability with concave microsites collecting water and competition reducing the amount of available water. Trembling aspen is also a shade intolerant species so vegetation competition which reduces the amount of light received may further reduce seedling survival after initial establishment (USDA 2008). The result of these exacting seedling establishment criteria is a narrow window of opportunity for seedling establishment of only a few weeks within each growing season, allowing seedling establishment to occur mostly within the first six years after a disturbance (Greene et al. 1999).

The main cover soil types used in oil sands reclamation are forest floor-mineral mix (FFMM) and peat-mineral mix (PMM), both of which may offer suitable establishment sites for deciduous tree seedlings. Forest floor-mineral mix is a mixture of upland forest floor surface organic material and the underlying mineral soil. It is a preferred reclamation soil as it contains numerous plant propagules from the natural forest stand (Mackenzie and Naeth 2010), thereby promoting native plant establishment and offering a more natural establishment substrate for tree seedlings. Peat-mineral mix is a mixture of lowland organic peat deposits and the underlying mineral soil. This soil type tends to have high organic matter content and an associated high moisture holding capacity which may make it an ideal substrate for seedling establishment. Previous greenhouse studies have shown that aspen germination does not differ among reclamation soil types but the development of initial foliar and root biomass was greater on FFMM than PMM (Pinno et al. 2012). Fertilization is also commonly used in oil sands reclamation as a means of ameliorating potential soil nutrient deficiencies (Pinno et al. 2012). However, fertilization may encourage the growth of competing vegetation such that the overall impact of fertilization on aspen seedling establishment is not clear (Sloan and Jacobs 2013). Another potential issue for natural seedling regeneration is soil compaction and the creation of smooth surfaces which have inadequate microsites for seedling germination (Bradshaw 2000), but this can be ameliorated by actively creating a rough surface.

The goal of this study was to quantify natural deciduous tree seedling establishment potential for different reclamation practices, including different soil types and fertilization applications, in an oil sands mine in northern Alberta, Canada. We also examined the impacts of environmental drivers, such as soil moisture, vegetative competition, and soil characteristics on initial seedling establishment and growth, at different spatial scales. The focus of this study was primarily on trembling aspen, which is the most common upland deciduous tree species in the study area.

\section{Methods}

This study was carried out on an 88.6 ha reclaimed overburden dump in northeastern Alberta, Canada at the Canadian Natural Resources Ltd. Horizon oil sands mine $75 \mathrm{~km}$ northwest of Fort McMurray (57 $\left.20^{\prime} \mathrm{N}, 111^{\circ} 49^{\prime} \mathrm{W}\right)$. This is an operational reclamation area which features relatively large but unreplicated areas of different soil types and fertilization applications which were incorporated into the study design. The natural ecosystem in the region is boreal mixedwood forest consisting of varying mixtures of deciduous (mainly trembling aspen) and coniferous, mainly white spruce (Picea glauca) trees on the upland sites (Beckingham and Archibald 1996). The climate is continental with mean temperatures in July of $16.8^{\circ} \mathrm{C}$ and January of $-18.8^{\circ} \mathrm{C}$ with a mean annual precipitation of 455 mm (Fort McMurray 1971-2000 Environment Canada climate normal). During the period of this study, annual precipitation was $285 \mathrm{~mm}, 451 \mathrm{~mm}$, and $392 \mathrm{~mm}$ in 2011, 2012, and 2013 respectively.

The overburden dump was constructed of saline-sodic overburden with cover soil placement in early 2011. The cover soil consisted of $1.5 \mathrm{~m}$ of suitable (non-saline) overburden topped with $0.5 \mathrm{~m}$ of directly placed mixture of organic matter and mineral soil derived from either an upland forest floor-mineral mix (FFMM) or a low lying peat-mineral mix (PMM). These are the most common reclamation cover soils used in the region and they differ substantially in organic matter content (Table 1). Soils were placed in four patches (two soil types $\times$ two fertilizer regimes) of approximately 20 ha each in size across the reclamation area. A fertilizer treatment (29.9-9.1-9.1-9.1 NPKS) was applied aerially to one patch per soil type at a rate of $100 \mathrm{~kg} \mathrm{~N} \mathrm{ha}^{-1}$ in summer 2011 and again in 2012 to the same patch for a total application of $200 \mathrm{~kg} \mathrm{~N} \mathrm{ha}^{-1}$. This immediately available fertilization formulation and rate was selected as it is the operational reclamation prescription currently used. The site was seeded with barley (Hordeum vulgare) in 2011 to control potential erosion and then planted with coniferous white spruce tree seedlings at a density of 1,500 seedlings per ha. The nearest trembling aspen seed source is from a mature stand approximately $300 \mathrm{~m}$ northeast of the reclamation area.

Data collection was based on 81 sampling points located systematically on a grid pattern across the entire reclamation area in summer 2013. The number of sampling points per reclamation treatment varied between 17 and 23 due to the exact shape and size of each treatment overlain with the systematic sampling grid.

To measure the availability of different microsite types, 16 microsite survey points were established around each of the 81 main sampling point centre posts (four microsites in each of the cardinal directions at a spacing of $1 \mathrm{~m}$ ). A microsite was considered to be a circular $15 \mathrm{~cm}$ diameter area and was classified according to slope, concavity, and 
Table 1. Soil properties for the different reclamation soil types at an oil sands mine in northern Alberta, Canada. Soil was derived from either an upland forest floor-mineral mix (FFMM) or a low lying peat-mineral mix (PMM). EC is electrical conductivity. SAR is sodium absorption ratio. Soil carbon was significantly greater in PMM compared to FFMM (ANOVA; $F=5.022, p=0.033$ ). $\mathrm{pH}$ and bulk density were not significantly different among treatments. $\mathrm{EC}$ and SAR were not able to be analyzed statistically.

\begin{tabular}{|c|c|c|c|c|c|}
\hline & $\begin{array}{c}\text { Carbon } \\
(\%)\end{array}$ & $\mathrm{pH}$ & $\begin{array}{c}\mathrm{EC} \\
\left(\mathrm{mS} \mathrm{cm} \mathrm{cm}^{-1}\right)\end{array}$ & SAR & $\begin{array}{c}\text { Bulk Density } \\
\left(\mathrm{g} \mathrm{cm}^{-1}\right)\end{array}$ \\
\hline FFMM—Not fertilized & 2.1 & 6.56 & 1.43 & 1.35 & 1.18 \\
\hline FFMM-Fertilized & 5.4 & 6.30 & 1.15 & 0.68 & 0.82 \\
\hline PMM-Not fertilized & 15.0 & 6.03 & 4.18 & 2.50 & 0.94 \\
\hline PMM-Fertilized & 15.4 & 6.02 & 3.76 & 2.79 & 0.75 \\
\hline
\end{tabular}

soil material. Slope was classified as flat $(<30 \%)$, shallow (31-60\%), or steep (>60\%). Concavity was classified as straight, concave, or convex with a minimum deviation of at least $2 \mathrm{~cm}$ from a straight line to be considered concave or convex. Soil material was classified as PMM, FFMM, mineral soil, or other (e.g., rock or wood).

At each sampling point, all deciduous seedlings were tallied within a $3.99 \mathrm{~m}$ radius $\left(50 \mathrm{~m}^{2}\right)$ and the microtopographic characteristics (i.e. slope, concavity, soil, and position) were recorded along with the height of each seedling. The topographic position of each plot on the reclamation landform was also classified as upper slope, lower slope or level. Around each sampling point, surface roughness was characterized as the maximum difference in surface elevation $(\mathrm{cm})$ within a horizontal distance of $1 \mathrm{~m}$. Surface roughness was measured five times in each plot and the results averaged. Differences in surface roughness were caused by the large equipment used in the mechanical placement of the reclamation cover soils.

A subset of 25 sampling points had additional soil and vegetation properties measured. These plots were specifically chosen in order to capture the entire range of regeneration densities found in each reclamation treatment and are part of a longer term tree growth study. Six sampling points were chosen from each reclamation treatment with two points randomly chosen from the lower, middle, and upper third of the tree seedling density range for each individual reclamation treatment. An extra sampling point was also included in the middle density range for the PMM without fertilization reclamation treatment. Soil moisture was measured twice during the growing season at a depth of $12 \mathrm{~cm}$ using a TDR soil moisture probe (Field Scout TDR 300, Spectrum Technologies Inc., Aurora, IL). Soil moisture values are an average of these two measurements. Soil bulk density was sampled at a depth of $5-10 \mathrm{~cm}$ by extracting a soil core of known volume $\left(88.7 \mathrm{~cm}^{3}\right)$. The soil sample was subsequently oven-dried at $60^{\circ} \mathrm{C}$ and then weighed to determine bulk density. Soils were then analyzed for total carbon, $\mathrm{pH}$, electrical conductivity, and sodium absorption ratio (Table 1). Total carbon (C) was determined for each soil by dry combustion and infra-red detection by the Dumas method using a LECO CN Analyzer. $\mathrm{pH}$ was determined using a saturated paste and electrical conductivity was determined from a saturated paste extract after a four hour contact. Sodium absorption ratio was calculated from $\mathrm{Na}, \mathrm{Mg}$, and Ca meq of a saturated paste extract. Due to the small sample volume, samples from each reclamation treatment were pooled for EC and SAR determination. Vegetation competition was estimated as total percent cover on four $1 \times 1 \mathrm{~m}$ quadrats systematically located around each sampling point.

The main response variables examined were seedling density and average height of the seedlings. Trembling aspen seedlings accounted for over $80 \%$ of the total number of seedlings measured, so for all analyses all deciduous seedlings were combined. Data analysis was conducted using SYSTAT 13 (SYSTAT Software Inc., Chicago, IL) with an $\alpha$ value of 0.05 being considered significant. As this was an operational reclamation area, the main treatments were not interspersed but rather consisted of large individual treatments patches of approximately 20 ha in size. All sampling points were at least $80 \mathrm{~m}$ apart and were considered independent replicates. At the reclamation treatment scale, a $2 \times 2$ ANOVA with soil (FFMM and PMM) and fertilizer (applied or not) as the main effects was used to examine seedling regeneration density and average seedling height.

Regression and regression tree analysis were used to relate seedling density and height to surface roughness, slope position, soil properties, and competition. These environmental variables were also compared between soil and fertilizer treatments using ANOVA. At the microsite scale, a preference rating was used based on the percentage of seedlings growing in a given microsite relative to the availability of that microsite (Landhäusser et al. 2010). Values of 1 indicate no preference for a microsite while greater values indicate a preference and lower values indicate avoidance. A paired t-test was used to determine if any of the microsite parameters had preference ratings different from 1 and ANOVA was used to compare seedling growth across microsite types.

\section{Results}

Naturally established tree seedlings were found in 53 out of 81 sampling points across the reclamation area. Of these 1,138 seedlings, 913 were trembling aspen, 223 were 


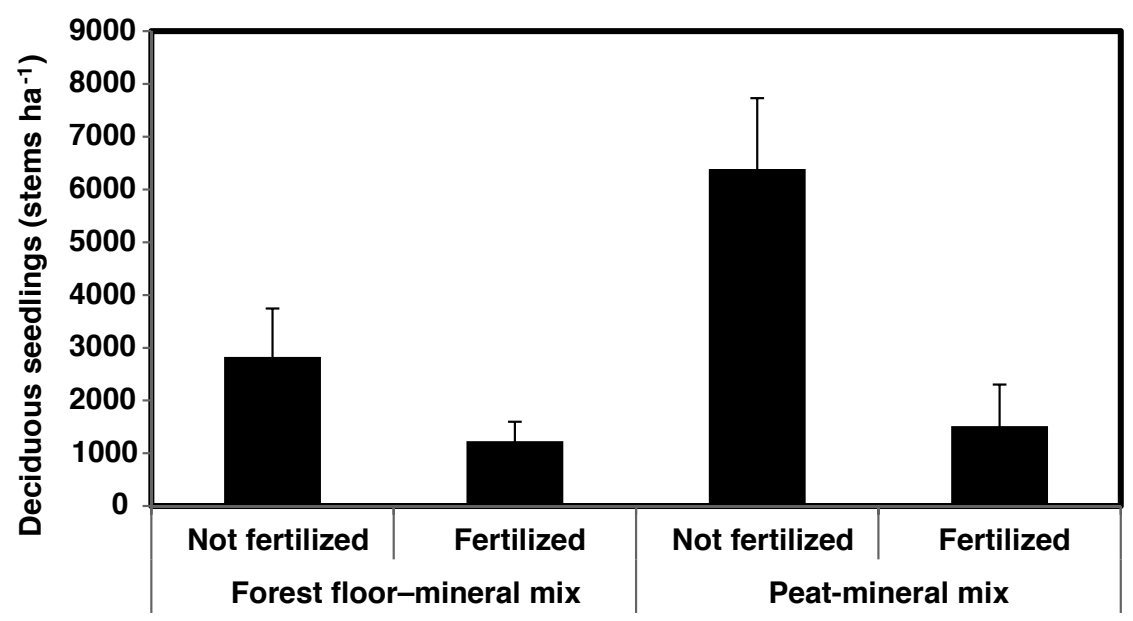

Figure 1. Deciduous tree seedling regeneration density by reclamation prescription at an oil sands mine in northern Alberta, Canada. Values are mean and standard error.

balsam poplar, and 2 were white birch (Betula papyrifera). No naturally established conifer seedlings were found. Average deciduous seedling establishment was greater on PMM than on FFMM (ANOVA; $\mathrm{F}=4.690, p=0.033$ ) and greater with no fertilizer than with fertilizer (ANOVA; F $=13.312, p<0.001$ ) such that the greatest seedling density is on PMM with no fertilization (average 6,388 seedlings $\mathrm{ha}^{-1}$ ) (Figure 1). There was no interaction between the main effects (ANOVA; $\mathrm{F}=3.410, p=0.069$ ).

None of the measured soil and site variables, such as surface roughness, soil moisture, vegetation competition cover, or bulk density, were linearly related to seedling density (linear regression; $p>0.05$ for all variables). However, regression tree analysis determined surface roughness to be the best predictor of seedling regeneration. Sampling points with surface roughness greater than $32 \mathrm{~cm}$ had significantly more seedlings than areas with less roughness (Figure 2A). The probability of having greater than 2,000 seedlings per ha (a common planting density; Alberta Environment, 2010) was $62 \%$ if surface roughness was greater than $32 \mathrm{~cm}$ compared to only $35 \%$ with lower surface roughness. Surface roughness was related to soil type with PMM (average $30.4 \mathrm{~cm}$ ) having significantly greater average roughness than FFMM (average $16.4 \mathrm{~cm}$ ) (ANOVA; $\mathrm{F}=18.592, p<0.001$ ). Based on the sub-sample of soil and vegetation properties from 25 sampling points, cover less than $51 \%$ had greater tree seedling regeneration than plots with greater cover (Figure 2B). Within the lower cover plots, high soil moisture (>56\%) was negatively related to seedling regeneration so that the highest level of seedling regeneration was found on plots with low cover and less than $56 \%$ soil moisture. Soil moisture was greater on PMM (average 52.0\%) than FFMM (average 33.6\%) (ANOVA; $\mathrm{F}=18.916, p=0.001$ ) but was unaffected by fertilization (ANOVA; $\mathrm{F}=0.439, p=0.514$ ). Vegetation cover was greater on FFMM than PMM (ANOVA; $F=56.837$, $p<0.001)$ and on fertilized compared to non-fertilized (ANOVA; $\mathrm{F}=5.602, p=0.013$ ) (Figure 4).

At the microsite scale, the most common slope class was shallow which occurred in $70.6 \%$ of the microsites and the most common concavity class was straight (78.1\%). However, none of the slope or concavity categories had seedling establishment preference ratings significantly different (t-test; $p>0.05$ ) from 1 indicating that seedlings established at microsites in proportion to microsite availability.

Average height of all seedlings across all treatments was $23 \mathrm{~cm}$ (range $3-160 \mathrm{~cm}$ ) and was not different among soil types (ANOVA; $\mathrm{F}=0.035, p=0.852$ ) or fertilization treatments (ANOVA; $\mathrm{F}=0.221, p=0.221$ ). Seedling height was not linearly related to any measured variables including surface roughness (linear regression, $p=0.180$ ), vegetative cover $(p=0.593)$, soil moisture ( $p=0.463)$, or bulk density $(p=0.130)$. At the microsite scale, concavity $(p=0.137)$ and slope $(p=0.645)$ were not related to seedling height.

\section{Discussion}

The establishment of deciduous tree seedlings was greatest on PMM soil material with no fertilization. This response was related to the increased surface roughness and soil moisture and the reduced competition levels of the PMM in comparison to the FFMM. Plots with greater surface roughness were associated with increased seedling establishment, perhaps because the increased surface roughness provided more of the preferred microsites, trapped more seeds, or influenced microclimatic effects such as reducing evaporation (Bradshaw 2000). On the other hand, smoother plots with less surface roughness may not have trapped as many windblown seeds or may have had more unfavourable soil conditions such as increased bulk density. Whatever the mechanism, it is clear that increased roughness was associated with greater seedling establishment and 


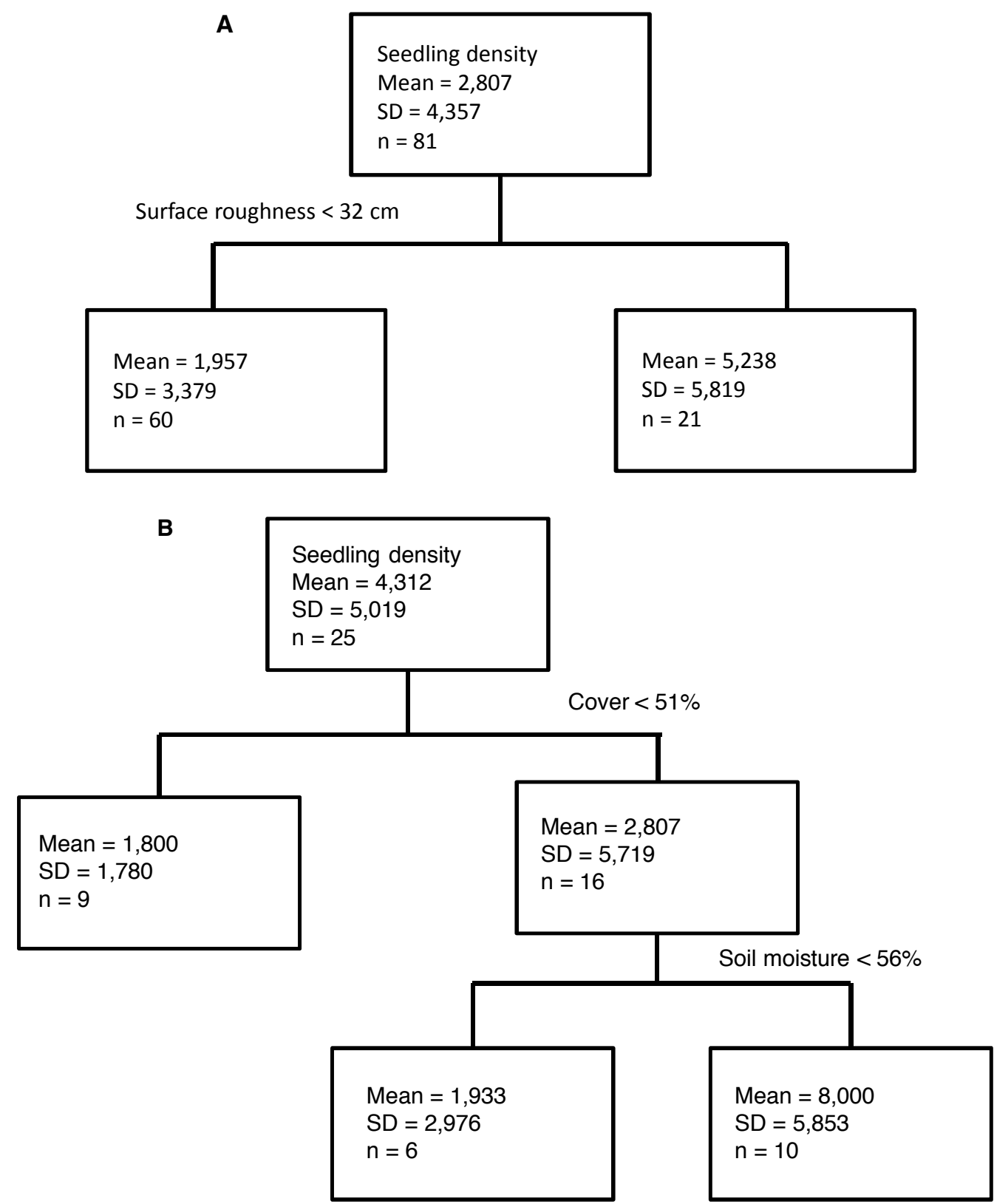

Figure 2. Regression tree analysis for deciduous seedling establishment (stems ha-1). A) Establishment in relation to surface roughness $(\mathrm{cm})$ of all 81 main plots (proportional reduction in error is 0.110 ). Other potential variables examined included topographic position and soil type. B) Establishment in relation to vegetation cover, soil moisture, and bulk density for the sub-set of $\mathbf{2 5}$ main plots (proportional reduction in error for the whole model is 0.374 ). All splits are significantly different at $p<0.05$. Each split in the regression tree identifies groups which are significantly different from each other in terms of seedling regeneration density. The mean seedling density, standard deviation and number of plots in each group are given in each box. The variable and value given at each decision node characterize the statistically significant groupings.

that this type of meso-scale surface expression was most common on the PMM soil. Within traditional forest management, site preparation and scarification produce similar surface roughness patterns and are used after harvesting to promote natural conifer seedling establishment due to the increase in available preferred seedbeds (Gärtner et al. 2011). It remains to be determined whether increased surface roughness can be combined with FFMM to increase potential seedling regeneration. While this may be possible,
FFMM has lower soil moisture and greater vegetative competition than PMM making seedling establishment responses hard to predict. In comparison, regeneration after a nearby natural forest fire resulted in stands with greater than 80,000 aspen suckers ha $^{-1}$ whereas common planting densities are 1,500-2,000 seedling ha ${ }^{-1}$ (Alberta Environment 2010). Natural seedling establishment on reclaimed sites appears to have regeneration potential between the post-fire sucker regeneration and planting standards. 


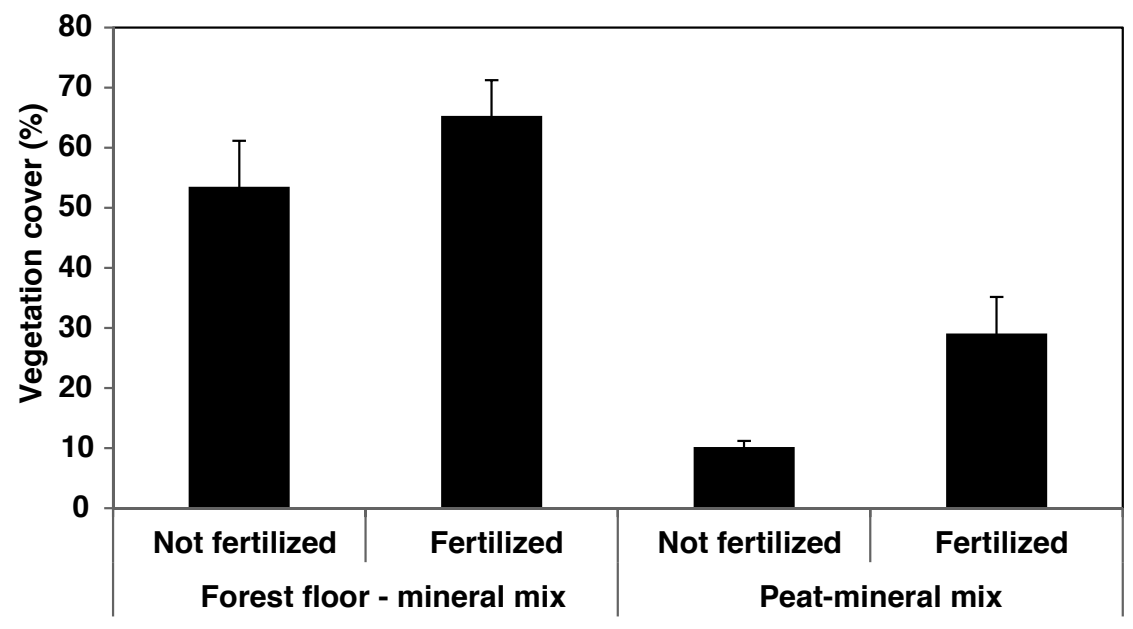

Figure 3. Vegetation cover by reclamation prescription. Values are mean and standard error.

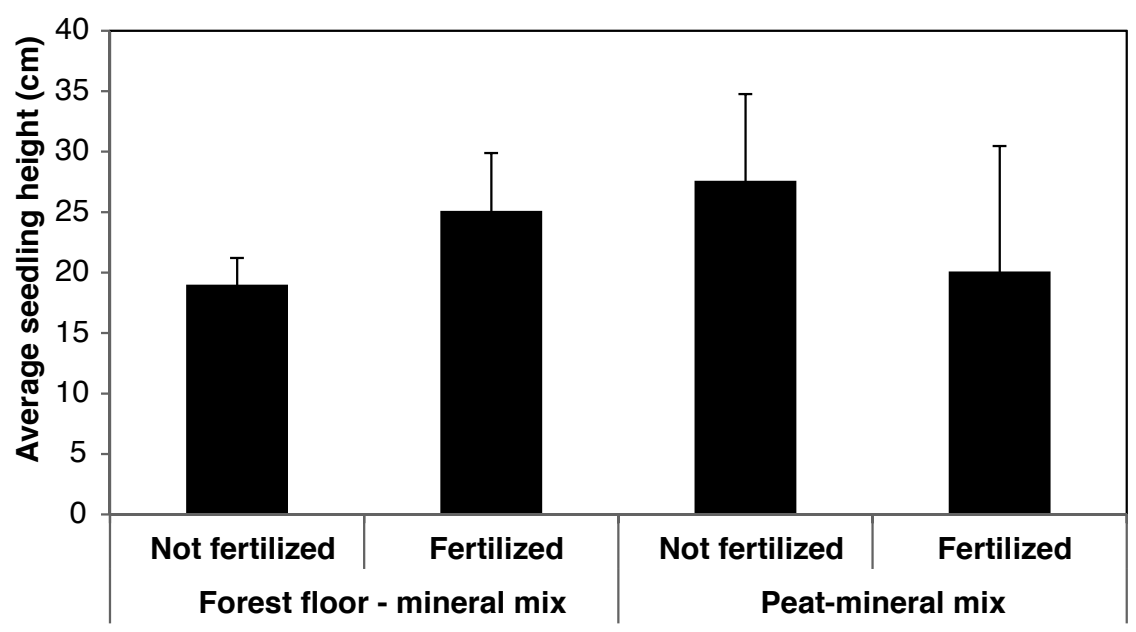

Figure 4. Average seedling height by reclamation prescription. Values are mean and standard error.

A constant supply of soil moisture has been shown to be crucial to aspen seedling establishment. In a greenhouse study, both low and high moisture levels were associated with reduced seedling establishment of aspen on mineral soils (Wolken et al. 2010). The inter-annual variability in soil moisture should also be taken into account since average soil moisture levels may be overridden by unusually high or low levels of precipitation. This has been shown in grassland restoration studies with year of seeding being a significant factor in native seedling establishment (Bakker et al. 2003). However, the greater organic matter content and associated water holding capacity in the PMM suggest that seedling establishment should be greater on PMM than FFMM in most years, and particularly in dry years. Seedling establishment was also reduced at vegetation competition levels above $51 \%$ cover confirming other studies that have shown reduced aspen seedling establishment due to vegetation competition after natural disturbances (Turner et al.
2003). It is important to note that seedling establishment showed clear thresholds to soil and site characteristics indicating that all of these variables, including surface roughness, soil moisture, and competition, can potentially impose constraints on seedling establishment. Therefore, if any of these variables are outside of the optimal range seedling establishment may be reduced.

Surprisingly, microsite did not appear to have a significant impact on natural seedling regeneration in this study. This is in contrast to other studies of natural aspen seedling establishment after timber harvesting which showed that aspen seedlings had a strong preference for concave microsites (Landhäusser et al. 2010). The lack of response to microsite may have been due to the large differences in soil properties between cover soil treatments obscuring any potential microsite effects on seedling regeneration. For example, the PMM mix had higher soil moisture than FFMM so perhaps microsite was not as important for this 
high organic matter content soil with high moisture holding capacity. Another possible explanation for this lack of microsite effect is that on newly constructed reclaimed sites, convex and concave microsites may not necessarily represent integrated moisture shedding and receiving areas like they do in natural environments which have undergone long-term erosion and deposition processes.

Average seedling growth was similar on all reclamation treatments; the main difference among treatments was on seedling establishment density. This supports the idea that aspen can grow equally well on a variety of different soil types that differ widely in their physical and chemical properties (Pinno and Bélanger 2012), such as FFMM and PMM. The lack of growth response to fertilization may be due to fertilization resulting in greater vegetation competition reducing potential tree growth (Sloan and Jacobs 2013). Delaying fertilization until after successful tree seedling establishment may result in greater nutrient uptake by the trees relative to the competing vegetation.

Overall, PMM had better deciduous seedling establishment compared to FFMM. Given that FFMM is known to have substantial benefits to understory species establishment compared to PMM (Mackenzie and Naeth 2010, Naeth et al.2013), it may be possible to combine these two common reclamation soil treatments spatially to maximize the potential benefits from both across the landscape. Care must be taken when extrapolating the results of this operational field trial to other reclamation sites because the soil and site characteristics will be different. For example, the surface roughness produced by the soil placement operation and the ratio of organic matter to underlying mineral soil are likely to be different at all reclamation sites. However, our results offer a starting point for best practices to maximize potential natural seedling regeneration on boreal mixedwood reclamation sites with PMM and increased surface roughness being associated with increased deciduous tree seedling establishment.

\section{Acknowledgements}

We thank Abby Lewis, Jesse Labatiuk and Edith Li for field work and Ira Sherr, Jim Stewart and Richard Krygier for helpful comments. Funding was provided by Canadian Natural Resources Ltd.

\section{References}

Alberta Environment. 2010. Guidelines for reclamation to forest vegetation in the Athabasca Oil Sands Region, $2^{\text {nd }}$ Edition. Prepared by the Terrestrial Subgroup of the Reclamation Working Group of the Cumulative Environmental Management Association. Fort McMurray, Alberta.

Bakker, J.D., S.D. Wilson, J.M. Christian, X. Li, L.G. Ambrose and J. Waddington. 2003. Contingency of grassland restoration over year, site, and competition from introduced grasses. Ecological Applications 13:137-153.
Barnes, B.V. 1966. The clonal growth habit of American aspens. Ecology 47:439-447.

Beckingham, J.D. and J.H. Archibald. 1996. Field Guide to Ecosites of Northern Alberta. Special Report 5, Canadian Forest Service, Northern Forestry Centre, Edmonton, AB.

Bradshaw, A. 2000. The use of natural processes in reclamationAdvantages and difficulties. Landscape and Urban Planning 51:89-100.

Clewell, A. and T. McDonald. 2009. Relevance of natural recovery to ecological restoration. Ecological Restoration 27:122-124.

Fechner, G.H., K.W. Burr and J.F. Myers. 1981. Effects of storage, temperature and moisture stress on seed germination and early seedling development of trembling aspen. Canadian Journal of Forest Research 11:718-722.

Frey, B.R., V.J. Lieffers, S.M. Landhäusser, P.G. Comeau and K.J. Greenway. 2003. An analysis of sucker regeneration of trembling aspen. Canadian Journal of Forest Research 33:1169-1179.

Gärtner, S.M., V.J. Lieffers and S.E. Macdonald. 2011. Ecology and management of natural regeneration of white spruce in the boreal forest. Environmental Reviews 19:461-478.

Greene, D.F., J.C. Zasada, L. Sirois, D. Kneeshaw, H. Morin, I. Charron and M.J. Simard. 1999. A review of the regeneration dynamics of North American boreal forest tree species. Canadian Journal of Forest Research 29:824-839.

Kay, C.E. 1993. Aspen seedlings in recently burned areas of Grand Teton and Yellowstone National Parks. Northwest Science 68: 94-104.

Landhäusser, S.M., D. Deshaies and V.J. Lieffers. 2010. Disturbance facilitates rapid range expansion of aspen in to higher elevations of the Rocky Mountains under a warming climate. Journal of Biogeography 37:68-76.

Macdonald, S.E., S.A. Quideau and S.M. Landhäusser. 2012. Rebuilding boreal forest ecosystems after industrial disturbance. Pages 123-160 in D.H.Vitt and J.S. Bhatti (eds), Restoration and reclamation of boreal ecosystems: Attaining sustainable development. New York, NY: Cambridge University Press.

Mackenzie, D.D. and M.A. Naeth. 2010. The role of the forest soil propagule bank in assisted natural recovery after oil sands mining. Restoration Ecology 18:418-427.

Martens, L.A., S.M. Landhäusser and V.J. Lieffers. 2007. First-year growth response of cold-stored, nursery-grown aspen planting stock. New Forests 33:281-295.

McDonough,W.T. 1979. Quaking aspen-Seed germination and early seedling growth. USDA Forest Service Research Paper INT-234.

Naeth, M.A., S.R. Wilkinson, D.D. Mackenzie, H.A. Archibald and C.B. Powter. 2013. Potential of LFH mineral soil mixes for reclamation of forested lands in Alberta. Oil Sands Research and Information Network, University of Alberta, School of Energy and the Environment, Edmonton, Alberta. OSRIN Report No. TR-35. 64 pp.

Pinno, B.D. and N. Bélanger. 2011. Estimating trembling aspen productivity in the boreal transition ecoregion of Saskatchewan using site and soil variables. Canadian Journal of Soil Science 91:661-669.

Pinno, B.D., S.M. Landhäusser, M.D. Mackenzie, S.A. Quideau and P.K. Chow. 2012. Trembling aspen seedling establishment, growth and response to fertilization on contrasting soils used in oil sands reclamation Canadian Journal of Soil Science. 92:143-151.

Rowland, S.M., C.E. Prescott, S.J. Grayston, S.A. Quideau and G.E. Bradfield. 2009. Recreating a functioning forest soil in reclaimed oil sands in northern Alberta: An approach for measuring 
success in ecological restoration. Journal of Environmental Quality 38:1580-1590.

Schott, K.M. 2013. Production and outplanting success of nutrientloaded aspen seedlings. MSc. Thesis. University of Alberta.

Sloan, J.L. and D.F. Jacobs. 2013. Fertilization at planting influences seedling growth and vegetative competition on a post-mining boreal reclamation site. New Forests 44:687-701.

Turner, M.G., W.H. Romme, R.A. Reed and G.A. Tuskan. 2003. Postfire aspen seedling recruitment across the Yellowstone (USA) landscape. Landscape Ecology 18:127-140.

USDA NRCS. 2008. Plant Guide: Quaking aspen Populus tremuloides Michx.

Wolken, J.M., S.M. Landhäusser, V.J. Lieffers and M.F. Dyck. 2010. Differences in initial root development and soil conditions affect establishment of trembling aspen and balsam poplar seedlings. Botany 88:275-285.

Bradley D. Pinno (corresponding author), Natural Resources Canada, Canadian Forest Service, Edmonton, Alberta, Canada,T6G3S5, bpinno@nrcan.gc.ca.

Ruth C. Errington, Natural Resources Canada, Canadian Forest Service, Edmonton, Alberta, Canada, T6G 3S5, rerringt@nrcan.gc.ca.

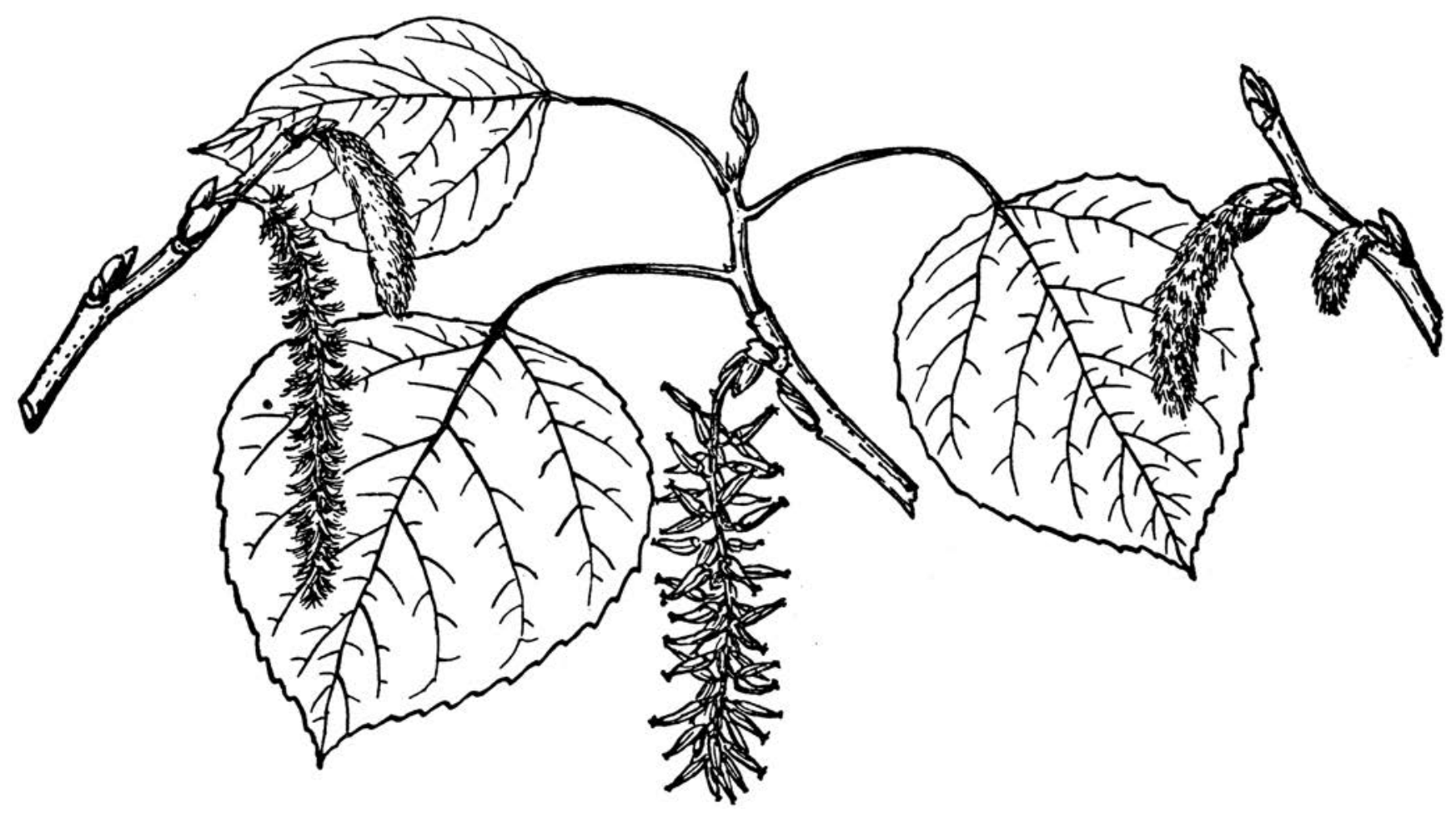

Populus tremuloides. Sargent, C. S. 1905. Manual of the Trees of North America, Boston, MA: Houghton Mifflin Company. The Florida Center for Instructional Technology, fcit.usf.edu. 